\title{
PEMODELAN PROSES BISNIS MANAJEMEN ASET MENGGUNAKAN TOGAF ARCHITECTURE DEVELOPMENT METHOD Studi Kasus: STMIK XYZ Surakarta
}

\author{
Sri Harjanto ${ }^{1)}$, Setiyowati ${ }^{2)}$ \\ ${ }^{1,2)}$ Program Studi Manajemen Informatika, STMIK Sinar Nusantara Surakarta \\ ${ }^{1)}$ sriharjanto@ sinus.ac.id, ${ }^{2}$ setiyowati@ sinus.ac.id
}

\begin{abstract}
STMIK XYZ is one of the universities in Surakarta. There are still some potential problems that interfere its business process, that is the asset inventory process as one of the asset management function. It needs long time to know the assets, their condition and position. In addition, the data entry is less optimal as well. Therefore this research is aimed at designing a business architecture which is capable to integrate the main business activities using TOGAF ADM framework. The existence of assets is a problem that runs in STMIK in STMIK XYZ. Thus it needs to make an architecture for the development of the Information System as well as the analysis and the business process modelling. It is hoped that the performance of the institution can meet the objective achievement and its improvement on the business process. This study uses Modelling Notation (BPMN) and TOGAF ADM methods to identify the needs and Business Process Reengineering $(B P R)$ in the development of the household information system. The final goal of this study is to make an asset management plan using the TOGAF ADM method.
\end{abstract}

Keywords: Asset Management, Business Process, TOGAF ADM, Business Process Reengineering, Business Process Modelling Notation

\section{PENDAHULUAN}

STMIK XYZ adalah salah satu institusi pendidikan tinggi di Surakarta. Berdasarkan wawancara dan observasi yang dilakukan terdapat beberapa informasi permasalahan yang berpotensi mengganggu aktivitas proses bisnisnya. Permasalahan yang terjadi dalam proses adalah untuk mengetahui ketersediaan aset yang siap untuk digunakan serta keberadaan aset tersebut mengakibatkan terganggunya kegiatan operasional dari proses bisnis yang terjadi di STMIK XYZ.

Sebagai salah satu perguruan tinggi yang orientasinya pada pelayanan jasa kependidikan dituntut untuk meningkatkan kualitas dan mutu pelayanan institusi yang prima. Sehingga dibutuhkan evaluasi perbaikan dan peningkatan yang berkelanjutan pada proses bisnis di STMIK XYZ agar proses bisnis dapat berjalan lebih efektif dan efisien. Dari masalah yang telah dipaparkan pada STMIK XYZ, maka perlu dilakukan mengidentifikasi kebutuhan dan identifikasi proses bisnis yang berjalan saat ini, dengan menggunakan metode TOGAF Architecture Development Method (ADM). Dilakukan evaluasi proses bisnis yang baku untuk memaksimalkan kinerja institusi dalam mencapai tujuan dari hasil evaluasi tersebut nantinya dapat dilakukan untuk perbaikan proses bisnis dengan teknik perbaikan Business Process Reenginering (BPR) yang akan direkomendasikan pada STMIK XYZ.

Tujuan dari penilitian ini yaitu untuk membuat arsitektur pengembangan Sistem Informasi pada tahap perencanaan dan identifikasi kebutuhan sistem di bagian kerumahtanggaan STMIK XYZ, mengetahui tata kelola kebutuhan sistem manajemen aset, untuk mengetahui arsitektur bisnis sistem manajemen aset, dan memberikan rekomendasi proses bisnis dengan Business Process Reengineering (BPR) di STMIK XYZ. 


\section{TINJAUAN PUSTAKA}

\subsection{Manajemen Aset}

Manajemen Aset adalah cara dan ciri dalam mengatur, merencanakan, mendesain, dan memonitor dalam proses mengakuisisi, memelihara, memperbarui, dan pembuangan segala bentuk infrastruktur dan aset teknis, untuk mendukung pengadaan servis publik. Aset Manajemen adalah sesuatu yang sistematik, suatu proses yang terstruktur, mencakupi seluruh umur hidup suatu Aset fisik (Brown, et al., 2012). Tujuan utama dari manajemen aset adalah membantu suatu organisasi dalam memenuhi tujuan penyediaan pelayanan secara efektif dan efisien (Hidayat, 2012).

\subsection{TOGAF ADM}

TOGAF merupakan metode yang detil dalam membangun, mengelola serta mengimplementasikan arsitektur enterprise dan sistem informasi yang disebut dengan Architecture Development Method (ADM) pada Gambar 1.

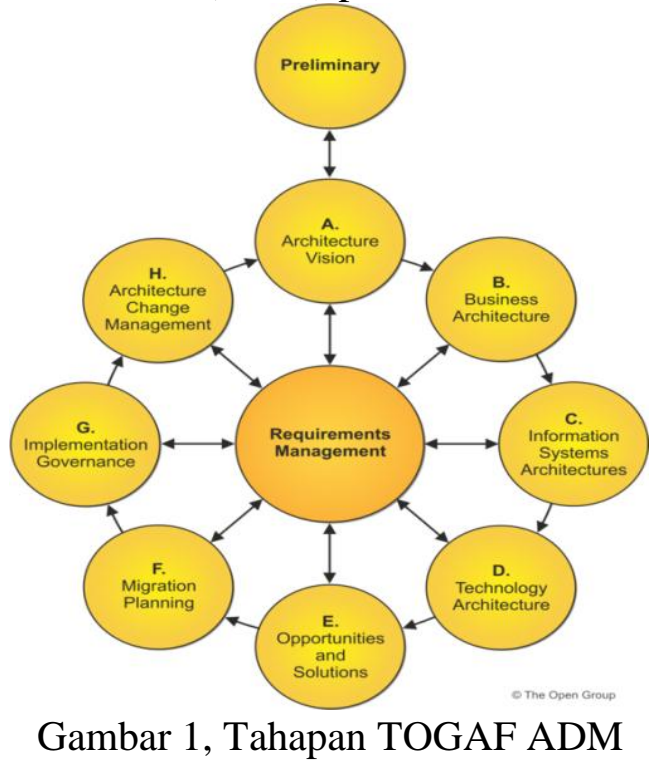

Architecture Development Method (ADM) merupakan metode yang berisi sekumpulan aktivitas yang digunakan dalam pemodelan pengembangan arsitektur perusahaan. Metode ini juga digunakan sebagai panduan untuk merencanakan, merancang, mengembangkan dan mengimplementasikan arsitektur perusahaan. TOGAF ADM bersifat Iterative, dinamis, serta berkelanjutan. Pada tiap keluaran dari fasenya akan menjadi masukan dari fase berikutnya. Dibutuhkan modifikasi dalam pengembangan ADM untuk menyesuaikan kebutuhan spesifik (T O G, 2016).

1. Preliminary Phase Tahap awal dalam dalam fase preliminary adalah menentukan ruang lingkup STMIK XYZ yang akan dijadikan sebagai objek penelitian, informasi mengenai dasar hukum sebagai acuan dari STMIK XYZ, pendefinisian tools arsitektur yang akan digunakan, dan pendefinisian prinsip-prinsip arsitektur enterprise. Pada tahap ini perlu adanya Requirement Management untuk penentuan kebutuhan arsitektur enterprise, kemudian dimasukkan dalam fase yang sesuai. Fase ini dilakukan proses pengelolaan kebutuhan arsitektur dan memvalidasi kebutuhan di seluruh fase TOGAF ADM. Kebutuhan utama dalam fase ini adalah proses bisnis dan permasalahan dalam STMIK XYZ yang berjalan saat ini. 
2. Phase A: Architecture Vision merupakan tahap pendefinisian ruang lingkup perencanaan proses bisnis yang ada saat ini. Tahap ini juga mendefinisikan profil, visi dan misi, dan strutur organisasi STMIK XYZ.

3. Phase B: Business Archtecture ini dilakukan melalui pemodelan arsitektur bisnis. Arsitektur bisnis digambarkan menggunakan tool Business Process Modelling Notation (BPMN).

\subsection{Business Process Modelling Notation}

Business Process Modelling Notation (BPMN) menyediakan representasi grafis untuk menentukan proses bisnis dalam suatu permodelan proses bisnis. Tujuan utama dari BPMN adalah menyediakan suatu notasi standar yang mudah dipahami oleh semua pemangku kepentingan bisnis ( Object Management Group, 2011).

\subsection{Analisis Fit/Gap}

Analisis fit/gap adalah metode yang digunakan oleh perusahaan dimana proses perusahaan dan fungsi sistem dibandingkan, dievaluasi, dan dicatat untuk menemukan kesesuaian (fit) dan ketidaksesuaian (gaps) (K.Kendall and J. Kendall, 2013). Fit menunjukkan kesesusaian kebutuhan oleh sistem, Gap menunjukkan tidak terpenuhi oleh sistem.

\subsection{Business Process Reengineering}

Business Process Reengineering (BPR) adalah pemikiran ulang yang mendasar dan rancangan ulang secara radikal dari suatu proses bisnis untuk mencapai perbaikan yang dramatis. Dengan mengukur kinerja saat ini melalui elemen-elemen biaya, kualitas, pelayanan, dan kecepatan”. Definisi BPR menekankan pada perancangan ulang suatu proses bisnis yang menantang praktik tengah berjalan dan bertujuan menghasilkan perbaikan atau peningkatan kinerja dalam proses bisnis yang signifikan (Hammer and Champy, 1993).

\section{METODE PENELITIAN}

Data dikumpulkan menggunakan dua sumber data yaitu data primer dan data skunder dengan tujuan untuk mendapatkan data yang akurat. Wawancara dilakukan pada stakeholder yang terkait seperti, bagian kerumahtanggaan maupun yang terlibat dalam manejemen aset. Penelitian ini juga menggunakan sumber data sekunder untuk mendapatkan informasi antara lain buku, jurnal dan paper. Alur penelitian seperti Gambar 2.

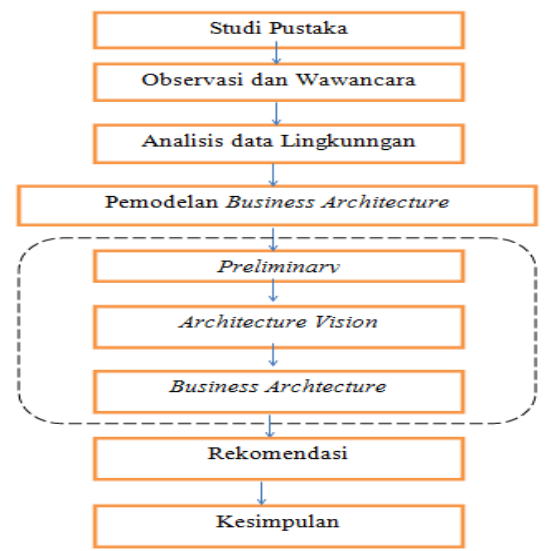

Gambar 2 Alur Penelitian 
Langkah analisis lingkungan dan inisiasi kebutuhan untuk menunjang perencanakan arsitektur bisnis menggunakan Analisis Value chain. Dari data dan analisis yang terkumpul pada aktor atau pelaku proses bisnis pada perusahaan digambarkan, proses bisnis menggunakan Business Process Modelling Notation, melakukan perencanaan teknik perbaikan dengan Business Process Reenginering kemudian penelitian ini membuat kesimpulan terkait proses bisnis pada STMIK XYZ.

\section{HASIL DAN PEMBAHASAN}

\subsection{Analisis}

Perancangan dimulai dengan identifikasi area fungsional utama STMIK XYZ yang terkait dengan unit organisasi dan aliran informasi menggunakan konsep value chain dari Porter. Michael Porter value chain digunakan untuk menjabarkan kegiatan utama dan kegiatan pendukung (Astri and Gaol, 2013). Value chain pada kerumahtanggaan STMIK XYZ di seperti pada Gambar 3 yang terdiri atas antara aktivitas utama dan aktivitas pendukung untuk memberikan output pada pengguna. Kegiatan utama meliputi Inbound Logistics: perencanaan dan pengadaan aset, Operations: pengoperasian aset, Sales and Marketing: pemeliharaan aset, Outbound Logistics: penghapusan aset, dan Service: layanan penggunaan aset. Kegiatan pendukung meliputi: pengelolaan keuangan dan administrasi, Pengelolaan teknologi informasi, manajemen kepegawaian, dan manajemen sarana prasarana.

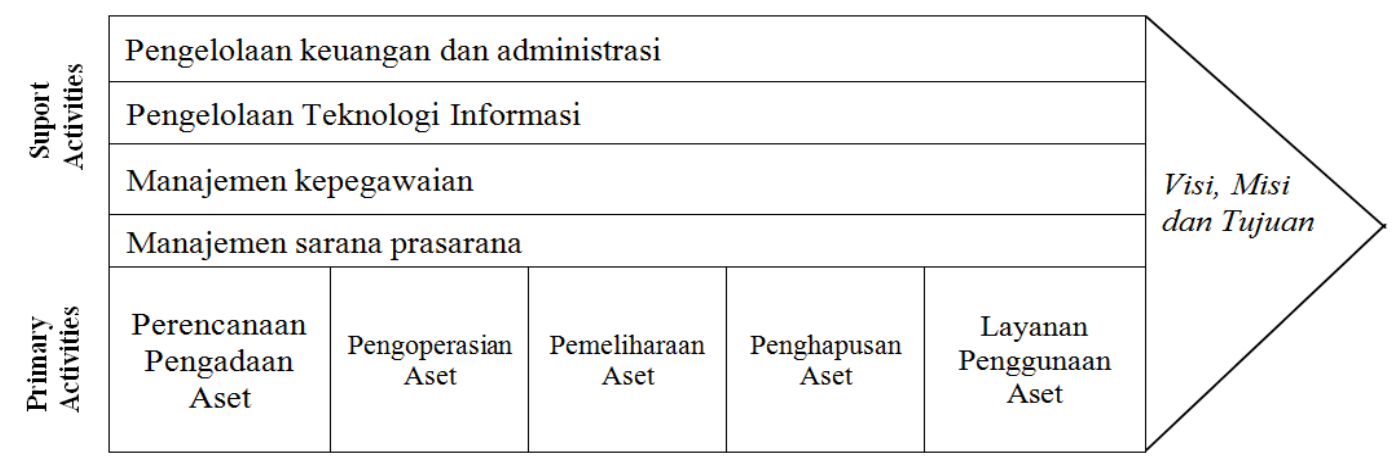

Gambar 3 Analisis Value Chain

\subsection{Preliminary}

Pada tahap awal TOGAF ADM adalah fase preliminary dilakukan untuk menentukan ruang lingkup perusahaan yang akan dijadikan sebagai objek penelitian, informasi tentang dasar hukum yang dijadikan acuan oleh perusahaan, pendefinisian tools arsitektur yang akan digunakan, dan pendefinisian prinsip-prinsip arsitektur enterprise. Dilakukan requirement management untuk menentukan kebutuhan arsitektur enterprise yang akan diidentifikasi, disimpan, dan dimasukkan dalam tahapan ADM yang sesuai. Skenario aktivitas menjadi sumber daya utama yang dikembangkan pada tahap ini. Skenario aktivitas terdiri dari core business dan process business yang dikelola oleh STMIK XYZ. Dalam core business STMIK XYZ memiliki bisnis utama yaitu melakukan pengelolaan aset meliputi pengadaan, pemindahan serta perawatan aset untuk meningkatan pengelolaan aset. Pelaksanaan tugas tersebut diwujudkan dengan aktivitas setiap harinya berupa pengadaan, perawatan, dan penggunaan dalam proses bisnisnya baik terhadap internal maupun eksternal STMIK XYZ. Hal ini dipengaruhi pemanfaatan teknologi informasi yang memfasilitasi semua aktivitas proses bisnis utama maupun aktivitas pendukung. 


\subsection{Architecture Vision}

Fase ini Architecture Vision menggambarkan batasan dari rancangan arsitektur dengan mendefinisikan ruang lingkup untuk memaparkan profil, visi misi, dan struktur organisasi STMIK XYZ.

\subsection{Business Architecture}

Fase ini akan mendeskripsikan serta memodelkan arsitektur bisnis saat ini dan rekomendasi model proses bisnis yang sesuai dengan tujuan dan sasaran STMIK XYZ.

\subsubsection{Proses bisnis saat ini}

Pemodelan proses bisnis dibuat hanya fokus pada fungsi bisnis utama yang memiliki permasalahan yang signifikan pada proses manajemen aset secara umum pada Gambar 4.

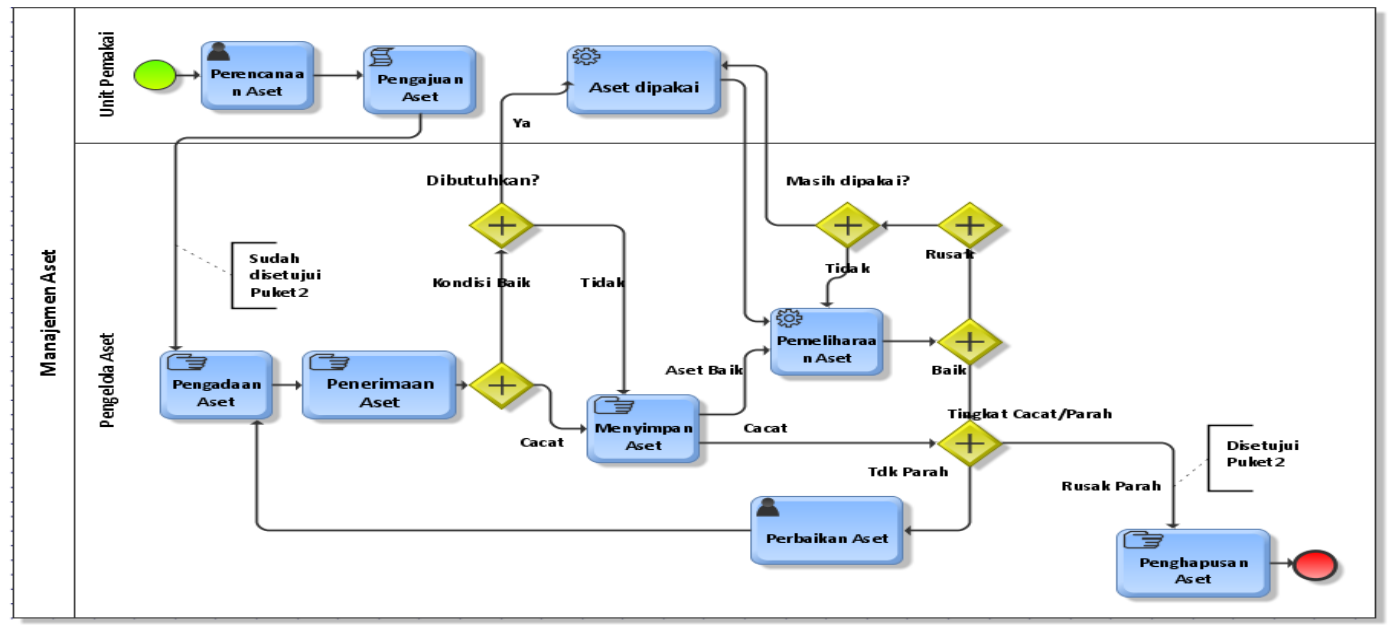

Gambar 4. Manajemen aset saat ini

Pemodelan proses bisnis pada masing-masing bagian dalam struktur organisasi memiliki tugas terkait dengan manajemen aset. Tabel 1 akan dijelaskan tentang deskripsi dari proses bisnis pengelolaan aset yang dilakukan oleh STMIK XYZ.

Tabel 1 Deskripsi Proses Bisnis saat ini

\begin{tabular}{|l|l|}
\hline Nama Proses Bisnis & Manajemen Aset \\
\hline Aktor Yang Terlibat & Unit Pemakai, Pengelola Aset. \\
\hline & $\begin{array}{l}\text { Proses bisnis pengadaan aset berdasarkan permintaan dari unit } \\
\text { pemakai (bagian atau karyawan), membuat perencanaan aset untuk } \\
\text { diajukan ke bagian operasional aset. membuat pengajuan aset, } \\
\text { Pengajuan aset yang disetujui oleh puket 2, akan merealisasikan } \\
\text { pengadaan aset. Realisasi aset yang ada dibuatkan berita acara } \\
\text { peskripsi Proses } \\
\text { Bisnis }\end{array} \quad \begin{array}{l}\text { aset yang dipakai perlu perbaikan atau perawatan maka perlu ada } \\
\text { kontrol untuk pengetahuan pihak operasional aset. Bila dalam } \\
\text { pemakaian aset tersebut dalam kondisi cacat atau rusak maka perlu di } \\
\text { periksa kondisinya jika masih dapat digunakan perlu perbaikan } \\
\text { pengadaan aset baru untuk pengganti, dan jika aset dalam kondisi } \\
\text { rusak parah maka akan dilakukan penghapusan aset dengan } \\
\text { persetujuan puket2 }\end{array}$ \\
\hline
\end{tabular}




\subsubsection{Rekomendari Proses Bisnis Yang Diharapkan}

Rekomendasi proses bisnis dirancang merupakan perbaikan proses bisnis manajemen aset yang disarankan oleh peneliti supaya dapat diterapkan pada STMIK XYZ Gambar 5.

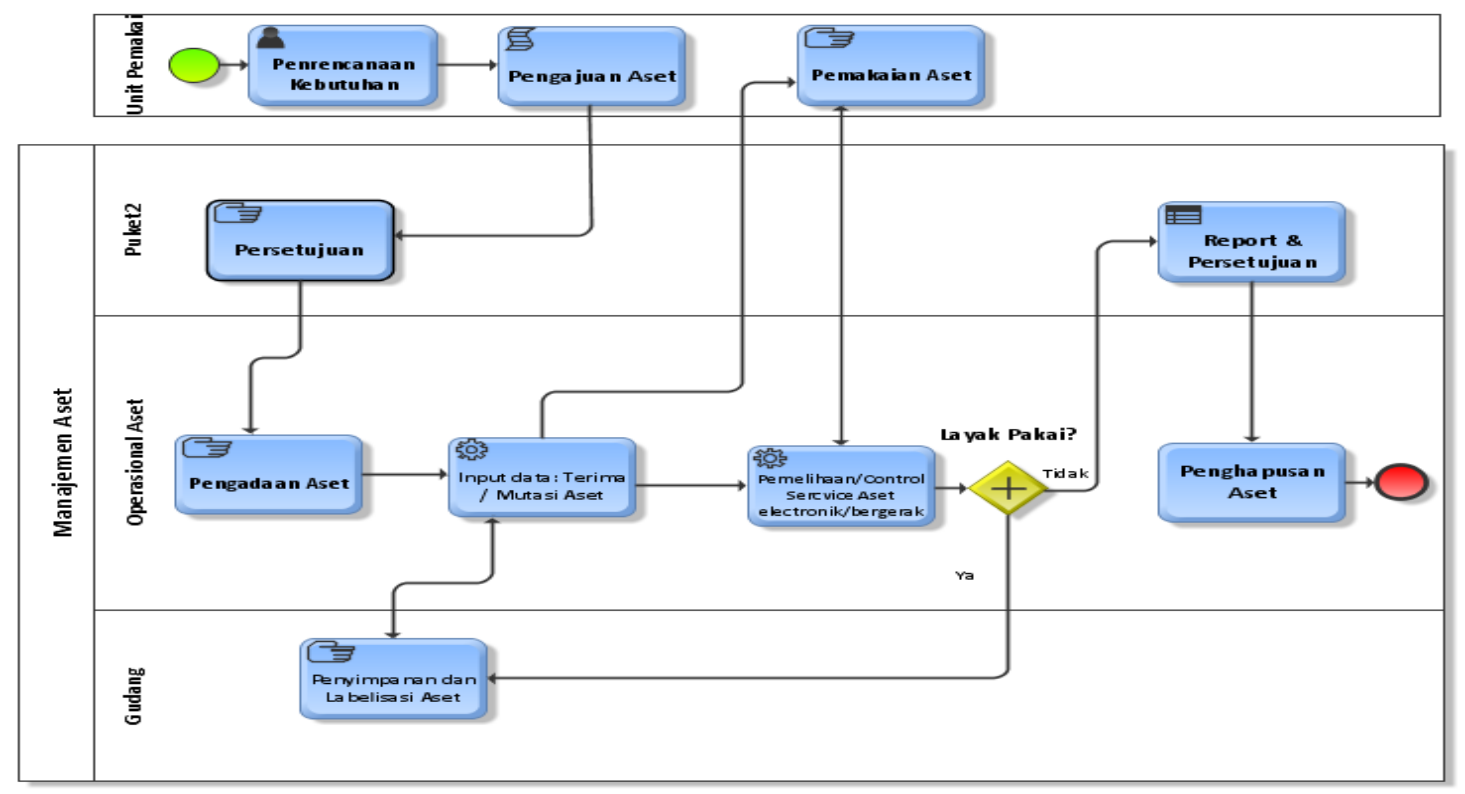

Gambar 5. Proses bisnis yang dirancang

Proses bisnis yang diusulkan melibatkan beberapa aktor sesuai dengan fungsi bisnis dalam struktur organisasi yang terkait manajemen aset dijelaskan dalam Tabel 2.

Tabel 2 Deskripsi Proses Bisnis yang dirancang

\begin{tabular}{|l|l|}
\hline Nama Proses Bisnis & Manajemen Aset \\
\hline Aktor Yang Terlibat & Unit Pemakai, Operasional aset, Gudang, Puket 2 \\
\hline Proses bisnis pengadaan aset berdasarkan permintaan dari unit pemakai \\
(bagian atau karyawan), dimulai setelah perencanaan aset, membuat \\
pengajuan aset yang sudah disetujui oleh puket2. Bagian operasional \\
aset merealisasikan pengadaan aset dari dasar pengajuan yang disetujui \\
di catat dalam sistem serta pemberian label oleh bagian Gudang. Dari \\
aset yang ada dibuatkan berita acara secara sistem untuk penggunaan \\
aset tersebut pada yang berhak menerima sesuai pengajuan, di catat \\
secara mengenai spesifikasi aset berikut dengan kondisi serta \\
pemakaiannya. Aset yang belum digunakan akan disimpan didalam \\
gudang. Bagian operasional aset setiap periode memberikan laporan \\
kepada puket2, tentang keberadaan aset yang ada. Aktifitas yang \\
berhubungan dengan aset, baik pemakaian aset tersebut dalam \\
kondisinya cacat atau rusak maka perlu di periksa kondisinya jika \\
masih dapat digunakan perlu pengadaan aset baru untuk pengganti, jika \\
aset dalam kondisi rusak parah, maka dilakukan penghapusan aset \\
dengan persetujuan puket2 semuanya tercatat SIMASET.
\end{tabular}


Adapun perbedaan sebelum dan sesudah diadakannya BPR dapat dilihat pada Tabel 3. Tabel 3. Tabel sebelum dan sesudah BPR

\begin{tabular}{|l|l|l|}
\hline No & Sebelum dilakukan BPR & Sesudah dilakukan BPR \\
\hline 1 & Proses kerja dilakukan secara manual & Proses kerja terkomputerisasi \\
\hline 2 & $\begin{array}{l}\text { Proses kerja antar bagian atau karyawan tidak ada } \\
\text { koordinasi, sehingga akan mengalami kesulitan } \\
\text { dalam pelacakan barang }\end{array}$ & $\begin{array}{l}\text { Proses antar bagian atau karyawan } \\
\text { ada koordinasi }\end{array}$ \\
\hline 3 & $\begin{array}{l}\text { Untuk mengetahui kondisi keberadaan aset di bagian } \\
\text { pengelolaan aset membutuhan waktu karena } \\
\text { pencarian data dilakukan secara manual di buku } \\
\text { pencatatan aset }\end{array}$ & $\begin{array}{l}\text { Waktu untuk mengetahui kondisi } \\
\text { aset dilakukan di bagian operasional } \\
\text { aset dengan pencarian } \\
\text { menggunakan sistem aplikasi } \\
\text { SIMASET. }\end{array}$ \\
\hline
\end{tabular}

\section{KESIMPULAN DAN SARAN \\ 5.1 Kesimpulan}

Dari hasil perencanaan dan inisiasi sistem manajemen aset di bagian kerumahtanggaan pada STMIK XYZ terdapat pendefinisian ruang lingkup yang saling mempengaruhi. Framework TOGAF ADM mencakup Preliminary Phase, Phase A: Architecture Vision dan Phase B: Business Architecture. Pendefinisian untuk memahami tools yang digunakan dalam memodelkan proses bisnis yaitu Business Process Modelling Notation. Prinsip menentukan architecture dilakukan untuk panduan atau arahan dalam mencapai tujuan STMIK XYZ dimana terdapat prinsip pengembangan sistem informasi, pengarsipan berkas fisik secara digital berbasis teknologi basis data, dan pengolaan data sebagai aset perusahaan. Dari hasil perencanaan arsitektur bisnis terdapat bagian atau aktor yang terlibat dalam proses bisnis manajemen aset dan setiap aktor mempunyai fungsi bisnis. Dari langkah-langkah aktivitas dan model proses bisnis menggunakan BPMN, dapat disimpulkan bahwa proses bisnis yang ada pada STMIK XYZ perlu alternatif perbaikan untuk meningkatkan efektifitas dan efisiensi pada proses bisnis yang berjalan saat ini.

Dari analisis yang telah dilakukan menghasilkan usulan disain arsitektur bisnis yang mampu mengintegrasikan aktivitas binis utama dengan menggunakan framework TOGAF ADM dan dukungan aktivitas dari pihak manajemen STMIK XYZ. Hal ini juga menunjukkan bahwa Arsitektur Bisnis menjadi salah satu komponen kunci untuk menentukan seberapa baik IT telah selaras dengan tujuan bisnisnya.

\subsection{Saran}

Usulan desain arsitektur bisnis dapat berjalan apabila didukung pihak manajemen dan segenap aktor terkait komitmen bersama dalam menjalankan prosedur yang disepakati.

\section{DAFTAR PUSTAKA}

Brown, K., Laue, M., Keast, r., Mahmood, N.,Wiewiora, A., \& Montagomery-Hribar, J.(2012). Pedoman Sistem Terpadu Pengelolaan Aset yang Strategis. Brisbane, Australia: Hanna Murphy.

Hammer, Michael, and Champy, James (1993), Reengineering the Corporation: A Manifesto for Business Revolution, Harper Business

Hidayat, M. (2012). Manajemen aset: Privat danPublik. Yogyakarta: LaksBang PRESSindo. 
Kendall, K. K. (2013), System Analysis and Design. 8 ed. USA: Pearson Education. Upper Saddle River, New Jersey.

Astri, L., and Gaol, F. (2013). Information System Strategic Planning with Enterprise Architecture Planning. BINUS University, 7(msi.binus.ac.id), 23-27. Retrieved from http://msi.binus.ac.id/files/2014/03/05_Ford-Lumban-Gaol_OK.pdf

Object Management Group. 2011. Bussines Process Modelling and Notation (BPMN) . Needham: OMG.

T. O. G., (2016). The Open Group TOGAF 9.1. from The Open Group TOGAF 9.1, 19 Mei 2018,open.Website:http://pubs.opengroup.org/architecture/togaf9-doc/arch/index.html. 